\title{
PENGARUH DAYA TARIK WISATA, KEPEKAAN LINGKUNGAN, DAN KEPUASAAN LAYANAN TERHADAP KETERIKATAN TEMPAT SERTA IMPLIKASINYA PADA SIKAP BERPRILAKU BERTANGGUNG JAWAB LINGKUNGAN
}

\author{
Wahyu Heryanto Putra ${ }^{1 *}$ \\ ${ }^{1}$ Fakultas Ekonomi dan Bisnis, Universitas Bengkulu \\ wahyuheryantoputra@gmail.com \\ Fachri Eka Saputra ${ }^{2}$ \\ ${ }^{2}$ Fakultas Ekonomi dan Bisnis, Universitas Bengkulu \\ fachri_mgt@unib.ac.id \\ *Korespondensi: wahyuheryantoputra@gmail.com
}

\begin{abstract}
This study aims to examine the effect of destination attractiveness, environmental sensitivity, satisfaction with interpretive services, toward place attachment. This study also aims to identify the effect of place attachment to environmental responsible behaviour. This study was using questionnaire as data collection method. The total sample of this study was 400 respondents. However, the number of questionnaires that can be processed was 398. The data were proccesed using PLS SEM (Partial Least Square). The result were obtained in this study: (1) destination attractiveness influences positive significant place attachment (2) environmental sensitivity influences positive significant place attachment (3) satisfaction with interpretive services influences positive significant place attachment (4) place attachment influences positive significant environmental responsible behaviour (5) destination attractiveness influences positive significant environmental responsible behaviour (6) environmental sensitivity influences positive significant environmental responsible behaviour (7) satisfaction with interpretive services influences positive significant environmental responsible behaviour. This research contributes to the literature on tourism marketing.
\end{abstract}

Keywords: Destination attractiveness, environmental sensitivity, environmental responsible behaviour, place attachment, satisfaction with interpretive services.

\section{PENDAHULUAN}

Pariwisata telah menjadi salah satu sektor ekonomi terbesar yang mempunyai tingkat pertumbuhan paling pesat tiap tahun dan menjadi sumber 
utama pendapatan bagi banyak negara di dunia. Perkembangan sektor pariwisata di Indonesia semakin meningkat tiap tahun. Hal ini ditunjukkan oleh banyaknya jumlah kunjungan dan pendapatan devisa negara baik dari wisatawan mancanegara maupun domestik di berbagai daerah provinsi di Indonesia. Salah satu Provinsi di Indonesia yang mengalami peningkatan kunjungan wisatawan mancanegara dan domestik yaitu Provinsi Bengkulu. Berbagai faktor yang bisa meningkatkan perkembangan sektor pariwisata khususnya Provinsi Bengkulu salah satunya, sikap perilaku bertanggung jawab dan peduli terhadap lingkungan, karena sikap perilaku bertanggung jawab dan peduli terhadap lingkungan di era saat ini menjadi salah satu faktor penting dalam kemajuan suatu daerah khususnya di sektor pariwisata.

Namun, saat ini masih banyak perilaku wisatawan mancanegara maupun wisatawan domestik yang tidak bertanggung jawab terhadap lingkungan wisata seperti, membuang sampah sembarangan, merusak fasilitas-fasilitas sehingga dapat merusak dan mencemari lingkungan wisata. Dampak dari perilaku-perilaku yang tidak bertanggung jawab ini, banyak lokasi wisata yang menerapkan aturanaturan untuk menjaga dari perilaku yang tidak bertanggung jawab. Sehingga perilaku bertanggung jawab terhadap lingkungan penting ditingkatkan, karena sikap perilaku bertanggung jawab dan peduli terhadap lingkungan akan menciptakan suasana lingkungan yang bersih dan indah (Scannell \& Gifford, 2010). Salah satu faktor untuk menciptakan lingkungan bersih dan indah dengan meningkatkan sikap berprilaku bertanggung jawab lingkungan.

Sikap berprilaku bertanggung jawab lingkungan mengacu pada tindakan yang dilakukan individu atau kelompok sebagai cerminan kekhawatiran mereka terhadap lingkungan sekitar (Cheng, C. Wu, \& Huang, 2013). (Scannell \& Gifford, 2010) dalam studinya menjelaskan jika wisatawan memiliki niat untuk menunjukkan perilaku bertanggung jawab terhadap lingkungan, secara efektif mereka akan mengurangi kerusakan terhadap lingkungan. Hal ini akan membuat mereka lebih sadar bahwa masalah lingkungan harus ditangani dan segera diselesaikan (Bamberg \& Möser, 2007).

Dolnicar \& Leisch (2008) menjelaskan bahwa keterikatan tempat merupakan faktor penting yang menimbulkan sikap berprilaku bertanggung jawab lingkungan, sehingga wisatawan yang memiliki keterikatan tempat tinggi cenderung akan memiliki sikap berprilaku bertanggung jawab lingkungan tinggi pula. Keterikatan tempat merupakan ikatan emosional seseorang yang positif terhadap suatu lokasi yang spesifik (Scannell \& Gifford, 2010). Keterikatan tempat juga menghubungkan seseorang dengan lingkungan dan membangkitkan rasa kepedulian terhadap lingkungan (Moore \& Graefe, 1994). Para peneliti menggunakan Keterikatan tempat untuk mengeksplorasi perilaku wisatawan, sehingga mengetahui keinginan, emosi, 
dan perilaku wisatawan (Hou, Lin, \& Morais, 2005). (Chiu, Lee, \& Chen, 2014) dalam studinya menjelaskan bahwa wisatawan dengan tingkat keterikatan tempat yang lebih tinggi akan menunjukkan sikap berprilaku bertanggung jawab lingkungan, sehingga wisatawan akan menjaga dan melindungi lingkungan agar bersih dan tidak rusak. Hal ini dapat menjadikan lingkungan tersebut memiliki nilai daya tarik wisata.

Daya tarik wisata mengacu pada persepsi wisatawan tentang daya tarik yang dimiliki suatu tempat wisata yang memberikan kepuasan dan manfaat untuk memenuhi kebutuhan mereka (Hu \& Ritchie, 1993). (Hou et al., 2005) menemukan bahwa daya tarik wisata memiliki pengaruh yang positif signifikan dalam menentukan pilihan wisatawan, ketika berkunjung ke suatu tempat. Wisatawan akan tertarik terhadap suatu tempat wisata, ketika wisata tersebut memiliki daya tarik wisata yang tinggi sehingga menjadi destinasi wisata yang wajib dikunjungi. Selain daya tarik wisata faktor lain yang memengaruhi keterikatan tempat dan sikap berprilaku bertanggung jawab lingkungan yaitu kepekaan lingkungan.

Kepekaan lingkungan adalah karakteristik yang dimiliki seseorang yang peka terhadap lingkungan sekitar (Williams \& Vaske, 2003). (Williams \& Vaske, 2003) dalam studinya menemukan bahwa kepekaan lingkungan ialah sikap seseorang untuk tertarik mempelajari tentang lingkungan, kepedulian terhadap lingkungan, dan bertindak untuk menjaga dan merawat lingkungan yang didasarkan oleh pengalaman seseorang terhadap tempat-tempat tertentu. (Chawla, 1998) mengatakan bahwa kepekaan lingkungan adalah variabel yang memengaruhi keterikatan tempat dan sikap berprilaku bertanggung jawab lingkungan. Apabila wisatawan memiliki kepekaan yang tinggi terhadap lingkungan, mereka akan menunjukkan sikap berprilaku bertanggung jawab lingkungan. Faktor lainnya yang juga memengaruhi keterikatan tempat dan sikap berprilaku bertanggung jawab lingkungan yaitu kepuasan layanan.

Zhao \& Timoth (2017) mengatakan bahwa kepuasan layanan tidak hanya meningkatkan kepuasan wisatawan, tetapi juga dapat menambah wawasan pengetahuan bagi wisatawan ketika berkunjung. kepuasan layanan umum digunakan di tempat rekreasi seperti taman dan tempat wisata lainnya yang memberikan informasi dan menyajikan pengetahuan tentang nilai-nilai sumber daya alam dan sejarah (Ham \& Weiler, 2007).

\section{TELAAH PUSTAKA}

Hubungan antara daya tarik wisata dan keterikatan tempat mendapat ketertarikan di kalangan peneliti. (Hou et al., 2005) menemukan bahwa daya tarik wisata berpengaruh positif dan signifikan terhadap keterikatan tempat. Temuan dari (Cheng et al., 2013) yang dilakukan di pariwisata alam di Penghu Taiwan juga 
menemukan hasil yang sama, bahwa daya tarik wisata berpengaruh positif dan signifikan terhadap keterikatan tempat, sehingga hipotesis 1 pada penelitian ini adalah: daya tarik wisata berpengaruh terhadap keterikatan tempat.

Temuan yang dilakukan (Cheng et al., 2013) yang dilakukan di pariwisata alam di Penghu Taiwan juga menemukan hasil yang sama, bahwa kepekaan lingkungan berpengaruh positif dan signifikan terhadap keterikatan tempat, sehingga hipotesis 2 pada penelitian ini adalah: kepekaan lingkungan berpengaruh terhadap keterikatan tempat. (Zhao et al., 2018) yang dilakukan di pariwisata Yuyuantan Urban Park China juga menemukan hasil yang sama, bahwa kepuasan layanan berpengaruh positif dan signifikan terhadap keterikatan tempat, sehingga hipotesis 3 pada penelitian ini adalah: kepuasan layanan berpengaruh terhadap keterikatan tempat.

Cheng et al., (2013) dan (Cheng \& Wu, 2015) juga menmukan hasil yang sama, bahwa keterikatan tempat berpengaruh positif dan signifikan terhadap sikap berprilaku bertanggung jawab lingkungan, sehingga hipotesis 4 pada penelitian ini adalah: keterikatan tempat berpengaruh terhadap sikap berprilaku bertanggung jawab lingkungan. Temuan dari (Cheng et al., 2013) yang dilakukan di pariwisata Penghu Taiwan juga menemukan hasil yang sama, bahwa daya tarik wisata berpengaruh langsung dan signifikan terhadap sikap berprilaku bertanggung jawab lingkungan, sehingga hipotesis 5 pada penelitian ini adalah: daya tarik wisata berpengaruh terhadap sikap berprilaku bertanggung jawab lingkungan. Temuan yang dilakukan (Cheng \& Wu, 2015) menemukan hasil yang sama, bahwa kepekaan lingkungan berpengaruh langsung dan signifikan terhadap sikap berprilaku bertanggung jawab lingkungan, sehingga hipotesis 6 pada penelitian ini adalah: kepekaan lingkungan berpengaruh terhadap sikap berprilaku bertanggung jawab lingkungan. (Zhao et al., 2018) dalam penelitianya bahwa keterikatan tempat berpengaruh langsung dan signifikan terhadap sikap berprilaku bertanggung jawab lingkungan, sehingga hipotesis 7 pada penelitian ini adalah: kepuasan layanan berpengaruh terhadap sikap berprilaku bertanggung jawab lingkungan.

Penelitian ini akan dilakukan di Kota Bengkulu khususnya wisata dark tourism, dimana Provinsi Bengkulu dikenal secara luas dengan kota yang kental akan sejarah dan budaya. Dark tourism adalah suatu tempat wisata yang memiliki kisah sejarah yang kelam seperti, kematian, peperangan, bencana atau tragedi serius ditempat tersebut yang terjadi di masa lampau atau pada abad pertengahan (Foley \& Lennon, 1996). Dark tourism memiliki banyak nilai bagi pengembangan pariwisata sehingga bisa menjadi jendela untuk memberikan pemahaman dan kesadaran pentingnya sejarah, sehingga dapat meningkatkan kesadaran dan kemampuan untuk menjaga dan merawat wisata agar tidak rusak. Konsep mengenai dark tourism ialah menawarkan sisi pendidikan dan emosional sebagai 
pengalaman berwisata, juga menyampaikan pesan yang berhubungan dengan kejadian masa lampau (Lennon \& Continuum, 2002). Wisata dark tourism yang ada di Kota Bengkulu yaitu, Benteng Marlborough, Rumah pengasingan Bung Karno, Rumah Ibu Fatmawati, Makam Inggris, dan Tugu Thomas Parr.

\section{METODE PENELITIAN}

Teknik pengambilan sampel yang digunakan dalam penelitian ini adalah teknik purposive sampling. Kriteria sampel yang digunakan dalam penelitian ini adalah wisatawan yang pernah berkunjung ke Kota Bengkulu, wisatawan yang mengetahui destinasi wisata dark tourism di Kota Bengkulu, wisatawan yang pernah berkunjung ke destinasi wisata dark tourism di Kota Bengkulu. Sampel dalam penelitian ini adalah sebanyak 398 responden. Metode pengumpulan data yang digunakan di dalam penelitian ini adalah dengan penyebaran kuesioner secara online dilakukan dengan cara memasukan kuesioner ke dalam Google Form, lalu kuesioner online disebarkan melalui media sosial grup travelling di facebook, whatsapp, instagram, dan twitter. Pengukuran variabel sikap berprilaku bertanggung jawab lingkungan menggunakan pengukuran dari (Cheng et al., 2013), keterikatan tempat menggunakan pengukuran dari (Prayag, Suntikul, \& Agyeiwaah, 2018), daya tarik wisata dan kepekaan lingkungan menggunakan pengukuran dari (Cheng et al., 2013), kepuasan layanan menggunakan pengukuran dari (Zhao et al., 2018). Pengukuran-pengukuran tersebut telah diuji validitas dan uji reliabilitas yang mana menunjukkan bahwa masing-masing indikator adalah valid dan setiap variabel dinyatakan reliable sehingga dapat digunakan untuk dianalisis. Metode analisis data dalam penelitian ini menggunakan SEM (Structural Equation Modelling) dengan menggunakan program PLS (Partial Least Square) versi 2.8.9.

\section{HASIL PENELITIAN DAN PEMBAHASAN Evaluasi Model Struktural}

Nilai $R$-square disajikan pada Tabel 1, berdasarkan prinsipnya penelitian ini menggunakan dua variabel endogen yang dipengaruhi oleh variabel lainnya. Variabel endogen dalam penelitian ini adalah keterikatan tempat yang dipengaruhi oleh variabel daya tarik wsiata, kepekaan lingkungan, dan kepuasan layanan. Variabel sikap berprilaku bertanggung jawab lingkungan dapat dipengaruhi oleh variabel daya tarik wsiata, kepekaan lingkungan, kepuasan layanan, dan keterikatan tempat. 
Tabel 1. $R$-square Variabel Endogen

\begin{tabular}{|c|c|c|}
\hline Konstruk Endogen & Konstruk Eksogen & R-Square \\
\hline Place Attachment & $\begin{array}{l}\text { Destination Attractiveness, environmental } \\
\text { sensitivity, satisfaction with interpretive } \\
\text { services }\end{array}$ & 0,469 \\
\hline $\begin{array}{l}\text { Environmental } \\
\text { Responsible } \\
\text { Behaviour }\end{array}$ & $\begin{array}{l}\text { Destination Attractiveness, environmental } \\
\text { sensitivity, satisfaction with interpretive } \\
\text { services }\end{array}$ & 0,464 \\
\hline $\begin{array}{l}\text { Environmental } \\
\text { Responsible } \\
\text { Behaviour }\end{array}$ & $\begin{array}{l}\text { Destination Attractiveness, Place } \\
\text { attachmnet }\end{array}$ & 0,516 \\
\hline $\begin{array}{l}\text { Environmental } \\
\text { Responsible } \\
\text { Behaviour }\end{array}$ & $\begin{array}{l}\text { Environmental sensitivity, Place } \\
\text { attachment }\end{array}$ & 0,517 \\
\hline $\begin{array}{l}\text { Environmental } \\
\text { Responsible } \\
\text { Behaviour }\end{array}$ & $\begin{array}{l}\text { Satisfaction with interpretive services, } \\
\text { Place attachment }\end{array}$ & 0,487 \\
\hline
\end{tabular}

Berdasarkan Tabel 1 untuk variabel keterikatan tempat diperoleh sebesar 0,469 yang menunjukan bahwa sebesar $46,9 \%$ variabel keterikatan tempat dapat dipengaruhi oleh variabel daya tarik wisata, kepekaan lingkungan, dan kepuasan layanan selebihnya sebesar $53,1 \%$ dijelaskan oleh faktor lain yang tidak dijelaskan dalam penelitian. $R$-square untuk variabel sikap berprilaku bertanggung jawab lingkungan diperoleh sebesar 0,464 yang menunjukan bahwa variabel sikap berprilaku bertanggung jawab lingkungan dipengaruhi oleh variabel daya tarik wisata, kepekaan lingkungan, dan kepuasan layanan sebesar $46,4 \%$, selebihnya dijelaskan oleh faktor lain slain konstruk tersebut yaitu sebesar $53,6 \%$. Selanjutnya, $r$-square untuk masing-masing jalur adalah 0,516 untuk sikap berprilaku bertanggung jawab lingkungan yang dipengaruhi oleh daya tarik wisata dan keterikatan tempat, berarti sebanyak $51,6 \%$ variabel sikap berprilaku bertanggung jawab lingkungan dapat dipengaruhi oleh daya tarik wisata dan keterikatan tempat. Jalur yang kedua, yaitu $r$-square sikap berprilaku bertanggung jawab lingkungan adalah 0,517 berarti sebesar $51,7 \%$ variabel sikap berprilaku bertanggung jawab lingkungan dapat dipengaruhi oleh kepekaan lingkungan dan keterikatan tempat. Kemudian jalur yang ketiga, $r$-square sikap berprilaku bertanggung jawab lingkungan diperoleh 0,487 hasil ini menunjukan bahwa sebesar $48,7 \%$ variabel sikap berprilaku bertanggung jawab lingkungan dapat dipengaruhi oleh variabel kepuasan layanan dan keterikatan tempat. 


\section{Hasil Pengujian Hipotesis}

Dalam PLS pengujian setiap hubungan yang dihipotesiskan dilakukan dengan metode bootstrapping. Untuk menilai tingkat signifikansi dalam pengujian hipotesis, skor total effect. yang ditunjukkan dari $t$-statistic antara variabel eksogen ke variabel endogen, harus di atas 1,96 pada hipotesis dua arah untuk pengujian pada alpha 5\% (Hair, Sarstedt, Pieper, \& Ringle, 2012). Hasil pengujian hipotesis dapat dilihat pada tabel berikut:

Tabel 2. Pengujian Hipotesis Menggunakan Bootstraping

\begin{tabular}{lccc}
\hline Hipotesis & t-Statistic & t-Tabel & $\begin{array}{c}\text { Hasil Uji (t-Statistic > } \\
\boldsymbol{t} \text {-Tabel) }\end{array}$ \\
\hline H1 (DA => PA) & 7,896 & 1,96 & DITERIMA \\
H2 (ES => PA) & 2,364 & 1,96 & DITERIMA \\
H3 (SI => PA) & 4,507 & 1,96 & DITERIMA \\
H4 (PA => ESB) & 6,676 & 1,96 & DITERIMA \\
H5 (DA => ESB) & 7,897 & 1,96 & DITERIMA \\
H6 (ES => ESB) & 4,498 & 1,96 & DITERIMA \\
H7 (SI => ESB) & 2,797 & 1,96 & DITERIMA \\
\hline
\end{tabular}

\section{Pembahasan}

\section{Daya tarik wisata berpengaruh terhadap keterikatan tempat pada destinasi wisata dark tourism Kota Bengkulu}

Penelitian ini bahwa daya tarik wisata memengaruhi terhadap keterikatan tempat. Hasil pengujian hipotesis menunjukkan bahwa dugaan ini diterima, yaitu terbukti daya tarik wisata berpengaruh terhadap keterikatan tempat. Pengaruh daya tarik wisata terhadap keterikatan tempat bersifat positif signifikan. Hasil penelitian ini mendukung temuan penelitian sebelumnya yang ditemukan oleh (Hou et al., 2005) hasil penelitianya menemukan bahwa daya tarik wisata berpengaruh positif dan signifikan terhadap keterikatan tempat yang dilakukan di sektor wisata budaya di Pei-Pu Taiwan. Hasil penelitian ini juga menunjukkan bahwa setiap indikator dari daya tarik wisata dapat terpenuhi dengan baik, ini dibuktikan bahwa responden terhadap daya tarik wisata memberikan penilaian dengan rata-rata tinggi. Hasil nilai rata-rata ini memberikan dampak positif terhadap keterikatan tempat, hal ini dikarenakan selama destinasi wisata dark tourism di Kota Bengkulu terjaga dari keasliannya atau keunikannya, maka keterikatan wisatawan terhadap destinasi juga akan mengakar kuat.

Secara praktis hasil penelitian ini juga memberikan kontribusi penting terutama bagi pemerintah maupun pemasaran pariwisata dalam mengembangkan destinasi wisata dark tourism di Kota Bengkulu yaitu, 1) Meningkatkan sarana 
akomodasi, tranportasi dan tempat-tempat restoran di sekitar wisata, terlihat dari penilaian responden bahwa fasilitas sarana dan prasarana di sekitar destinasi masih banyak kurang, baik dari segi transportasi, tempat penginapan, maupun restoran khas Kota Bengkulu. 2) Meningkatkan berbagai kegiatan aktivitas di lingkungan sekitar destinasi, terlihat dari penilaian responden bahwa lingkungan sekitar destinasi kurang menarik atau unik. Lingkungan merupakan bagian penting dari industri wisata, kualitas lingkungan harus mendapatkan perhatian utama. Keindahan, kebersihan, keramahan lingkungan merupakan satu kesatuan yang tak terpisahkan dalam meciptakan lingkungan yang unik.

\section{Kepekaan lingkungan berpengaruh terhadap keterikatan tempat pada destinasi wisata dark tourism Kota Bengkulu}

Penelitian ini bahwa kepekaan lingkungan memengaruhi terhadap keterikatan tempat. Hasil pengujian hipotesis menunjukkan bahwa dugaan ini diterima, yaitu terbukti kepekaan lingkungan berpengaruh terhadap keterikatan tempat. Pengaruh kepekaan lingkungan terhadap keterikatan tempat bersifat positif signifikan. Hasil penelitian ini mendukung temuan penelitian sebelumnya yang ditemukan oleh (Cheng \& Wu, 2015) hasil penelitianya menemukan bahwa kepekaan lingkungan berpengaruh positif signifikan terhadap keterikatan tempat. Hasil penelitian ini juga menunjukkan bahwa setiap indikator pengukuran memberikan hasil yang sangat baik. Seseorang yang peka terhadap lingkungan akan menunjukkan karakteristik peduli lingkungan seperti "menolak membuang sampah sembarangan di lingkungan sekitar" yang dapat merusak lingkungan (Hungerford \& Volk, 1990). Dari hasil penelitian yang telah dilakukan dapat diketahui bahwa penilaian reponden terhadap kepekaan lingkungan sangat tinggi. Hal ini menunjukkan bahwa responden dalam penelitian ini mayoritas memiliki karakter atau sifat kepekaan terhadap suatu lingkungan di wisata sejarah Kota Bengkulu sangat tinggi.

Secara praktis hasil penelitian ini memberikan beberapa kontribusi penting bagi kemajuan pariwisata dark tourism di Kota Bengkulu, yaitu Meningkatkan suasana alami dan unik di lingkungan sekitar destinasi, seperti membangun spot selfie bagi wisatawan yang berkunjung. Hal ini terlihat respon dari wisatawan yang memberikan penilaian sangat tinggi terhadap suasana dari destinasi wisata dark tourism di Kota Bengkulu. Sehingga ini akan mendorong wisatawan untuk lebih peduli dan menghargai terhadap lingkungan destinasi wisata dark tourism.

\section{Kepuasan layanan berpengaruh terhadap keterikatan tempat pada destinasi wisata dark tourism Kota Bengkulu}

Penelitian ini bahwa kepuasan layanan memengaruhi keterikatan tempat. Hasil pengujian hipotesis menunjukkan bahwa dugaan ini diterima, yaitu terbukti 
kepuasan layanan berpengaruh terhadap keterikatan tempat. Pengaruh kepuasan layanan terhadap keterikatan tempat bersifat positif signifikan. Hasil penelitian ini mendukung temuan penelitian sebelumnya yang ditemukan oleh (Zhao et al., 2018) hasil penelitianya menemukan bahwa kepuasan layanan berpengaruh positif signifikan terhadap keterikatan tempat. Hal ini menunjukan bahwa semakin baik pelayanan yang tersedia di wisata baik informasi ataupun fasilitas pendukung, maka semakin tinggi keterikatan seseorang terhadap tempat tersebut. (Ballantyne, Packer, \& Falk, 2011) dalam studinya menjelaskan bahwa wisatawan yang memiliki akses informasi mengenai wisata selama kunjungan mereka di suatu tempat akan mengubah sikap mereka terhadap lingkungan, sehingga akan menunjukan niat perilaku mereka untuk peduli terhadap lingkungan.

Secara praktis hasil penelitian ini juga memberikan kontribusi penting bagi pemerintah maupun pemasaran pariwisata dalam mengembangkan destinasi wisata dark tourism di Kota Bengkulu yaitu, Meningkatkan pelayanan informasi di destinasi pariwisata dark tourism, hal ini terbukti dari penilaian responden terhadap pelayanan informasi yang mereka terima, belum sepenuhnya memberikan pelayanan yang baik sehingga penilaian ini terbilang rendah dari lainya. Hal ini menjelaskan bahwa wisatawan mengalami kesulitan dalam mencari pelayanan informasi seputar objek-objek wisata. Upaya yang harus dilakukan antara lain membangun Pusat Informasi Pariwisata, agar menjadi panduan wisatawan ketika berkunjung.

Keterikatan tempat berpengaruh terhadap sikap berprilaku bertanggung jawab lingkungan pada destinasi wisata dark tourism Kota Bengkulu

Penelitian ini bahwa keterikatan tempat memengaruhi terhadap sikap berprilaku bertanggung jawab lingkungan. Hasil pengujian hipotesis menunjukkan bahwa dugaan ini diterima, yaitu terbukti keterikatan tempat berpengaruh terhadap sikap berprilaku bertanggung jawab lingkungan. Pengaruh keterikatan tempat terhadap sikap berprilaku bertanggung jawab lingkungan bersifat positif signifikan. Hasil penelitian ini mendukung temuan penelitian sebelumnya yang ditemukan oleh (Halpenny, 2006), hasil temuannya di sektor pariwisata alam dan budaya di Point Pelee National Park Canada, bahwa hubungan keterikatan tempat berpengaruh positif dan signifikan terhadap sikap berprilaku bertanggung jawab lingkungan. Hal ini menunjukkan bahwa semakin tinggi keterikatan seseorang terhadap suatu tempat wisata maka, akan meningkatkan sikap seseorang untuk bersikap peduli dan berprilaku bertanggung jawab terhadap lingkungan. (Ramkissoon, Weiler, \& Smith, 2012) dalam studinya menemukan bahwa seseorang yang memiliki keterikatan tempat terhadap tempat, berfungsi untuk menginterpretasikan 
pengalaman, harapan dan perilaku mereka ketika seseorang terikat pada suatu tempat, sehingga akan menunjukkan perilaku yang setia.

Secara praktis hasil penelitian ini juga memberikan kontribusi penting terutama bagi pemerintah maupun pemasaran pariwisata dalam mengembangkan destinasi wisata dark tourism di Kota Bengkulu yaitu, Memperjelas informasi sejarah tentang destinasi wisata dark tourism di Kota Bengkulu, hal ini terbukti bahwa responden masih banyak tidak memahami sejarah dari destinasi dark tourism, dikarenakan di lokasi wisata dark tourism masih minim informasi, seperti informasi asal usul sejarah berdirinya dan siapa pendirinya. Strategi yang dilakukan antara lain memasang papan petunjuk informasi, akan lebih baik lagi apabila petunjuk tersebut juga tersedia dalam multi-language (minimal tersedia dalam bahasa inggris, agar mempermudah informasi bagi wisatawan mancanegara.

\section{Daya tarik wisata berpengaruh terhadap sikap berprilaku bertanggung jawab lingkungan pada destinasi wisata dark tourism Kota Bengkulu}

Penelitian ini bahwa daya tarik wisata memengaruhi terhadap sikap berprilaku bertanggung jawab lingkungan. Hasil pengujian hipotesis menunjukkan bahwa dugaan ini diterima, yaitu terbukti daya tarik wisata berpengaruh terhadap sikap berprilaku bertanggung jawab lingkungan. Pengaruh daya tarik wisata terhadap sikap berprilaku bertanggung jawab lingkungan bersifat positif signifikan. Hasil penelitian ini mendukung temuan penelitian sebelumnya yang ditemukan oleh (Dolnicar \& Leisch, 2008) bahwa daya tarik wisata berpengaruh positif signifikan terhadap sikap berprilaku bertanggung jawab lingkungan. Temuan dari (Scannell \& Gifford, 2010) juga mengkonfirmasi dari penelitian sebelumnya bahwa daya tarik wisata berpengaruh positif signifikan terhadap sikap berprilaku bertanggung jawab lingkungan. Hal ini menunjukkan bahwa daya tarik suatu wisata akan meningkatkan sikap seseorang untuk bertanggung jawab dan peduli terhadap lingkungan. Daya tarik wisata menjadi acuan bagi para wisatawan ketika ingin mengunjungi suatu tempat destinasi, ketika suatu destinasi wisata memiliki daya tarik yang unik maka dapat merespon wisatawan untuk berkunjung bahkan memicu timbulnya sikap wisatawan untuk peduli dan bertanggung jawab terhadap lingkungan (Hu \& Ritchie, 1993).

Secara praktis hasil penelitian ini juga memberikan kontribusi penting bagi pemerintah maupun pemasaran pariwisata dalam mengembangkan destinasi wisata dark tourism di Kota Bengkulu yaitu, meningkatkan pengelolaan sampah di sekitar destinasi pariwisata. Pengelolaan ini perlu dilakukan agar tidak menganggu keindahan alam di sekitar kawasan wisata dark tourism. Strategi atau upaya yang harus dilakukan antara lain, memasang papan petunjuk himbauan membuang sampah, dan menyediakan tempat pembuangan sampah. 
Kepekaan lingkungan berpengaruh terhadap sikap berprilaku bertanggung jawab lingkungan pada destinasi wisata dark tourism Kota Bengkulu

Penelitian ini bahwa kepekaan lingkungan memengaruhi terhadap sikap berprilaku bertanggung jawab lingkungan. Hasil pengujian hipotesis menunjukkan bahwa dugaan ini diterima, yaitu terbukti kepekaan lingkungan berpengaruh terhadap sikap berprilaku bertanggung jawab lingkungan. Pengaruh kepekaan lingkungan terhadap sikap berprilaku bertanggung jawab lingkungan bersifat positif signifikan. Hasil penelitian ini mendukung temuan penelitian sebelumnya yang ditemukan oleh (Barnett et al., 2006) bahwa hubungan kepekaan lingkungan berpengaruh positif signifikan terhadap sikap berprilaku bertanggung jawab lingkungan. Hasil temuan terbaru dari (Cheng \& Wu, 2015) juga menyatakan bahwa kepekaan lingkungan terhadap sikap berprilaku bertanggung jawab lingkungan memiliki pengaruh yang positif signifikan. Hal ini menunjukkan bahwa semakin tinggi kepekaan seseorang terhadap lingkungan wisata, maka semakin tinggi sikap seseorang untuk bertanggung jawab dan peduli terhadap lingkungan. Hasil penelitian ini sejalan dengan penelitian sebelumnya, artinya hasil penelitian ini memperluas bukti empiris bahwa ada hubungan kepekaan lingkungan terhadap sikap berprilaku bertanggung jawab lingkungan di berbagai konteks objek yang berbeda termasuk pada objek wisata dark tourism di Kota Bengkulu.

\section{Kepuasan layanan berpengaruh terhadap sikap berprilaku bertanggung jawab lingkungan pada destinasi wisata dark tourism Kota Bengkulu}

Penelitian ini bahwa kepuasan layanan memengaruhi terhadap sikap berprilaku bertanggung jawab lingkungan. Hasil pengujian hipotesis menunjukkan bahwa dugaan ini diterima, yaitu terbukti kepuasan layanan berpengaruh terhadap sikap berprilaku bertanggung jawab lingkungan. Pengaruh kepuasan layanan terhadap sikap berprilaku bertanggung jawab lingkungan bersifat positif signifikan. Hasil penelitian ini mendukung temuan penelitian sebelumnya yang ditemukan oleh (Tsang, Yeung, \& Cheung, 2011) yang dilakukan di sektor pariwisata alam dan sejarah di Wetland Park Hongkong, bahwa kepuasan layanan berpengaruh langsung dan sginifikan terhadap sikap berprilaku bertanggung jawab lingkungan. Penelitian terbaru oleh (Zhao et al., 2018) juga mengkonfirmasi bahwa kepuasan layanan berpengaruh positif signifikan terhadap keterikatan tempat yang dilakukan di pariwisata Yuyuantan Urban Park China. Hal ini menunjukkan bahwa semakin baik tingkat fasilitas pelayanan, informasi, dan akomodasi yang tersedia di suatu destinasi wisata maka, akan meningkatkan seseorang untuk bersikap bertanggung jawab dan peduli terhadap lingkungan. Dari hasil penelitian yang telah dilakukan dapat diketahui bahwa hasil penelitian ini sejalan dengan penelitian sebelumnya, artinya hasil penelitian ini memperluas bukti empiris bahwa ada hubungan 
kepuasan layanan terhadap sikap berprilaku bertanggung jawab lingkungan terbukti di berbagai objek penelitian yang berbeda, termasuk pada objek wisata dark tourism di Kota Bengkulu. Sehingga hal ini dapat mendukung program prioritas Indonesia, yaitu "Visit Wonderfull Indonesia 2020", dan program prioritas Provinsi Bengkulu yaitu, "Visit Wonderfull Bengkulu 2020".

\section{KESIMPULAN DAN IMPLIKASI}

\section{Kesimpulan}

Simpulan yang didapatkan dari penelitian ini adalah ditemukan bahwa daya tarik wisata, kepekaan lingkungan, kepuasan layanan memengaruhi keterikatan tempat dan sikap berprilaku bertanggung jawab lingkungan secara positif dan signifikan pada objek destinasi wisata dark tourism di Kota Bengkulu.

\section{Implikasi}

Saran berupa yang dapat diberikan yaitu: (1) Meningkatkan dan membangun sarana akomodasi, dan fasilitas sarana prasarana yang mendukung; (2) Meningkatkan berbagai kegiatan aktivitas di lingkungan sekitar destinasi seperti Bencoolen Internasional Marine Festival; (3) Meningkatkan suasana alami dan unik di lingkungan sekitar destinasi seperti membangun spot selfie bagi wisatawan yang berkunjung; (4) Meningkatkan pelayanan informasi di destinasi pariwisata dark tourism Upaya yang harus dilakukan antara lain membangun Pusat Informasi Pariwisata; (5) Memperjelas informasi sejarah tentang destinasi wisata dark tourism di Kota Bengkulu, memasang papan petunjuk informasi; dan (6) Meningkatkan pengelolaan sampah di sekitar destinasi pariwisata.

\section{REFERENSI}

Ballantyne, R., Packer, J., \& Falk, J. J. T. m. 2011. Visitors' learning for environmental sustainability: Testing short-and long-term impacts of wildlife tourism experiences using structural equation modelling. 32(6): 1243-1252.

Bamberg, S., \& Möser, G. J. J. o. e. p. 2007. Twenty years after Hines, Hungerford, and Tomera: A new meta-analysis of psycho-social determinants of pro-environmental behaviour. 27(1): 14-25.

Barnett, M., Lord, C., Strauss, E., Rosca, C., Langford, H., Chavez, D., \& Deni, L. J. T. J. o. E. E. 2006. Using the urban environment to engage youths in urban ecology field studies. 37(2): 3-11.

Chawla, L. J. T. J. o. e. e. 1998. Significant life experiences revisited: A review of research on sources of environmental sensitivity. 29(3): 11-21.

Cheng, T.-M., C. Wu, H., \& Huang, L.-M. J. J. o. S. T. 2013. The influence of place attachment on the relationship between destination attractiveness and 
environmentally responsible behavior for island tourism in Penghu, Taiwan. 21(8): 1166-1187.

Cheng, T.-M., \& Wu, H. C. J. J. o. S. T. 2015. How do environmental knowledge, environmental sensitivity, and place attachment affect environmentally responsible behavior? An integrated approach for sustainable island tourism. 23(4): 557-576.

Chiu, Y.-T. H., Lee, W.-I., \& Chen, T.-H. J. T. m. 2014. Environmentally responsible behavior in ecotourism: Antecedents and implications. 40: 321-329.

Dolnicar, S., \& Leisch, F. J. J. o. T. R. 2008. An investigation of tourists' patterns of obligation to protect the environment. 46(4): 381-391.

Foley, M., \& Lennon, J. J. J. I. J. O. H. S. 1996. JFK and dark tourism: A fascination with assassination. 2(4): 198-211.

Hair, J. F., Sarstedt, M., Pieper, T. M., \& Ringle, C. M. J. L. r. p. 2012. The use of partial least squares structural equation modeling in strategic management research: a review of past practices and recommendations for future applications. 45(5-6): 320340.

Halpenny, E. A. 2006. Environmental behaviour, place attachment and park visitation: A case study of visitors to Point Pelee National Park.

Ham, S. H., \& Weiler, B. J. J. o. I. R. 2007. Isolating the Role of On-site Interpretation in a Satisfying Experience. 12(2).

Hou, J.-S., Lin, C.-H., \& Morais, D. B. J. J. o. T. R. 2005. Antecedents of attachment to a cultural tourism destination: The case of Hakka and non-Hakka Taiwanese visitors to Pei-Pu, Taiwan. 44(2): 221-233.

Hu, Y., \& Ritchie, J. B. J. J. o. t. r. 1993. Measuring destination attractiveness: A contextual approach. 32(2): 25-34.

Hungerford, H. R., \& Volk, T. L. J. T. j. o. e. e. 1990. Changing learner behavior through environmental education. 21(3): 8-21.

Lennon, J., \& Continuum, M. F. J. A. o. T. R. 2002. Dark tourism: the attraction of death and disaster. 29(4): 1188-1189.

Moore, R. L., \& Graefe, A. R. J. L. s. 1994. Attachments to recreation settings: The case of rail-trail users. 16(1): 17-31.

Prayag, G., Suntikul, W., \& Agyeiwaah, E. J. J. o. S. T. 2018. Domestic tourists to Elmina Castle, Ghana: motivation, tourism impacts, place attachment, and satisfaction. 26(12): 2053-2070.

Ramkissoon, H., Weiler, B., \& Smith, L. D. G. J. J. o. S. T. 2012. Place attachment and proenvironmental behaviour in national parks: The development of a conceptual framework. 20(2): 257-276.

Scannell, L., \& Gifford, R. J. J. o. e. p. 2010. The relations between natural and civic place attachment and pro-environmental behavior. 30(3): 289-297.

Tsang, N. K., Yeung, S., \& Cheung, C. J. A. P. J. o. T. R. 2011. A critical investigation of the use and effectiveness of interpretive services. 16(2): 123-137. 
Williams, D. R., \& Vaske, J. J. J. F. s. 2003. The measurement of place attachment: Validity and generalizability of a psychometric approach. 49(6): 830-840.

Zhao, M., Dong, S., Wu, H. C., Li, Y., Su, T., Xia, B., Zheng, J., \& Guo, X. J. A. P. J. o. T. R. 2018. Key impact factors of visitors' environmentally responsible behaviour: Personality traits or interpretive services? A case study of Beijing's Yuyuantan Urban Park, China. 23(8): 792-805.

Zhao, S. N., \& Timothy, D. J. J. A. O. T. R. 2017. Tourists' consumption and perceptions of red heritage. 63: 97-111. 